\title{
Towards a comprehensive methodology for applying enterprise gamification
}

\author{
Mohammad Fathian $^{\mathrm{a}, b^{*}}$, Hossein Sharifi ${ }^{\mathrm{c}}$, Elnaz Nasirzadeh $^{\mathrm{d}}$, Ronald Dyer ${ }^{\mathrm{e}}$ and Omar Elsayed
}

${ }^{a}$ Professor at School of Industrial Engineering, Iran University of Science and Technology, Tehran, Iran

${ }^{b}$ Honorary Associate of University of Liverpool Management School, Liverpool, United Kingdom

${ }^{c}$ Reader in Operations and Supply Chain Management, Management School, University of Liverpool, Liverpool, United Kingdom

${ }^{d}$ Ph.D Candidate of Information Technology (IT) Engineering, School of Industrial Engineering, Iran University of Science and

Technology, Tehran, Iran

eSenior Teaching Fellow, Management School, University of Sheffield, Sheffield, United Kingdom

${ }^{f}$ Ph.D Student, Management School, University of Liverpool, Liverpool, United Kingdom

\begin{tabular}{l}
\hline C H R O N I C L E \\
\hline Article history: \\
Received January 2, 2021 \\
Received in revised format: \\
March 12, 2021 \\
Accepted March 142021 \\
Available online \\
March 14, 2021 \\
\hline Keywords: \\
Gamification \\
Enterprise \\
Methodology \\
Game mechanics \\
Organizational gamification
\end{tabular}

\begin{abstract}
A B S T R A C T
Gamification as a new concept uses game elements in a novel way to engage users of a nongaming system and can be used in many domains within an enterprise, to implement the organizational processes with lower costs, higher quality or in a more efficient way. Although there are many researches on gamification but a few studies can be found in the organizational gamification and there are few research works about framework and methodology for designing and implementing organizational gamification in the literature. The purpose of this article is to provide a comprehensive methodology for the enterprise gamification. This research is an attempt to overcome the mentioned gap via presenting a methodology by applying some important issues including organizational, humanity and gamification aspects together to design and implement customized enterprise gamification solutions through reviewing the related literature and experts' commentaries. The evaluation of the methodology showed that it is an appropriate and perfect way to design gamification solutions in an organization, besides the enterprise needs to provide the necessary conditions for its implementation. This paper forwards an important debate on a comprehensive methodology for applying enterprise gamification, which explains how to properly use gamification in enterprises to increase productivity and better communication with employees, and thus contributes to literature on internal and enterprise gamification.
\end{abstract}

(C) 2021 by the authors; licensee Growing Science, Canada.

\section{Introduction}

Performance in organisations has been widely associated with employees' motivation and engagement (Anitha, 2014). According to the Gallup Employee Engagement Survey (2013), only 13\% of the employees in the 142 countries surveyed show satisfactory level of engagement with their work, which directly contributes to organisational low productivity (Gallup, 2013). Among the array of solutions to raise the level of employees' satisfaction in the workplace to better engage with their works to lead to improved behaviour, hence their performance, the concept of "Play" and its application in the form of games has had a special role. Technology assisted games (in non-game context), namely Gamification (Hamari, 2013), has proven a powerful approach to stimulate various organisational aspects such as engagement, collaboration and innovation (Zichermann \& Cunningham, 2011). Successful applications of gamification have been reported across different industries, attributed to its ability to utilise different psychological aspects that can tap into an individual's intrinsic motivators to provide an immersive and engaging environment for collaboration, innovation (Kapp, 2012). Other effects

\footnotetext{
* Corresponding author. Tel.: +9821-73225048

E-mail address: fathian@iust.ac.ir (M. Fathian)

(C) 2021 by the authors; licensee Growing Science, Canada.

doi: $10.5267 /$ j.dsl.2021.3.002
} 
such as increasing user activity, interactivity, productivity and quality of performing tasks have been reported as the outcome from games (Hamari, 2013; Ryan and Deci, 2000). Zichermann and Linder (2013) suggest three main aspects to be considered within a gamification approach: human behaviour; game design and individual psychology. Designing and implementing enterprise gamification can therefore be considered a relatively complex process, which should rely on a variety of analyses including enterprise and its goals and organisational structure, organisational culture, users, and also considerations and mechanisms for motivating, challenging, and rewarding the users (Neeli, 2015). While gamification may be treated as a system within an organisation, it involves a much wider set of behavioural factors which require proper attention in the process of its design and implementation. Appropriate frameworks and methodologies will be necessary for this purpose. Research in this area is in a nascent stage, and the literature only shows limited works in offering frameworks for the analysis and implementation of gamification systems (see Werbach, 2014; Dignan, 2011; Seaborne \& Fels, 2015; Hamari et al., 2014). A quick review of gamification literature reveals a number of gaps in this area. As discussed above, there are limited works and frameworks proposed for designing and implementing enterprise gamification. While varied perspectives have been applied in the existing frameworks, almost all of them offer an approach to the concept from a general point of view and lack the requirements of a comprehensive methodology for this purpose. For instance, very limited insight is offered for the relationship between the three key pillars of enterprise gamification, namely organisational characteristics, human traits and gamification. Also, the important aspect of customisation of gamification for specific needs of organisations, organisational units, individuals or occupational positions are not explicitly addressed.

This research is set out to address these gaps and present a case for a methodology for the enterprise gamification in order to address and overcome some of the mentioned gaps. The rest of the paper is organised as follows: first, we review the research literature and the research method. Then we describe how research data is collected, and the proposed methodology for the enterprise gamification will be introduced and explained, and finally the results of the evaluation of the methodology are expressed.

\section{Literature review}

Usually, work and play do not come together well, however, gamification gives the opportunity to mix the two (Kumar and Herger 2013). Gamification in essence can be explained as the concept of "play" combined with the idea of "technology" utilisation, to enable delivery of the game-like experience and achieve efficiency and effectiveness goals (Silva Ochoa, 2013; Sanchez et al., 2010). To understand the relationship between game and play, it can be said that games are concerned with entities, objects, and rules, while elements of play are concerned more with the players/users themselves (Silva Ochoa, 2013). In other words, the essence of a game is not in the entities by themselves, but in the enacted relationships and interrelations that are developed throughout the player experience within the game. According to Henriot (1969) playing is the degree to which a player is set to pursue and achieve certain predetermined goals and most importantly in a fun way. This highlights the factor of desire to play the game as an important element (Juul, 2010). According to Zimmerman (2004) a game is a voluntary interactive activity, in which one or more players follow the rules that constrain their behaviour, enacting an artificial conflict that ends in a quantifiable outcome. Gamification is based on the fact that human activities are carried out due to intrinsic motivations (Nicholson, 2015). Kark (2011) reported his research explaining how playing can be used to modify and stimulate certain behaviours using cognitive, affective and motivational factors. In other words, gamification is the use of the coordinates and the conditions of the game to solve problems through the modification of human behaviours. In fact, when daily activities of individuals are expressed in the form of the game and the environment of the gamification, their motivation and engagement will increase for their better performance (Iacovides, 2011). Therefore, the design process of the gamification should be a human-centred process. In gamification, fun is a central motivational factor that can drive certain behaviours and activities (Werbach, 2014). However, gamification is not just turning work into a game, but to facilitate engagement, motivation and learning through a serious process that can result in new insights, understandings and skills through an enjoyable activity (Kapp, 2012). This shows that fun is not the ultimate purpose of gamification, but a tool to reach higher development goals. The literature shows key potential effects of applying gamification within organisations including engagement, motivation, collaboration, knowledge sharing, learning and even stimulating innovation (Meloni and Gruener, 2012; Ryan and Deci, 2000; Kapp, 2012). Gamification as such has been received with a sense of anticipation to promise a new generation of assets that might be employed to enhance organisational capabilities. Gamification has been adopted lately in several contexts such as: facilitated learning, health and behavioural aspects, customer engagement and employee engagement and retention (Meloni and Gruener, 2012, Koivisto and Hamari, 2019). The existing literature on gamification shows a predominantly application development viewpoint as the approach taken. This can reduce the understanding of the concept to a tool for achieving a short-term organisational effect such as increasing employee engagement and stimulating collaboration or facilitating learning (Hamari et al., 2014; Werbach, 2014; Kapp, 2012). Aspects such as the developed enacted relationships and their respective outcomes are less attended in the literature.

\subsection{Gamification levels in enterprise}

According to Neeli (2012), gamification in an organization can be performed in different levels regarding integration degree between mechanics and organizational activities. In superficial level, the gamification mechanics are independent of activities while in integrated level, gamification mechanics are integrated into activities. At the deepest level, activities are 
designed based on mechanics. For example, activities are divided into tasks according to considered mechanics. Based on these three levels we can define two general approaches according to Fig. 1.

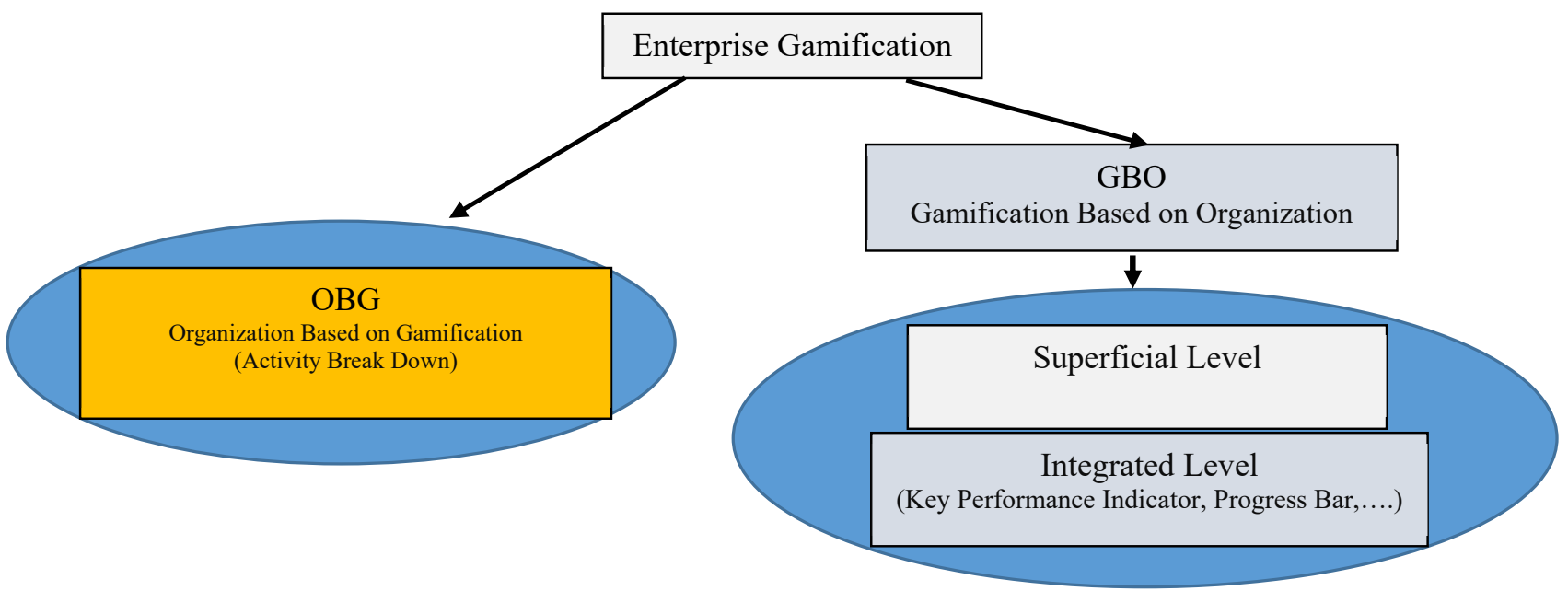

Fig. 1. Enterprise gamification-Two approaches

The first approach is to design gamification based on existing organizational activities (gamification based on organization) and in accordance with their conditions. The second approach is to design organizational activities based on gamification (organization based on gamification). In the Gamification Based on Organization (GBO), in fact we use game mechanics as tools for engagement of players (employees, customers, and partners) and increasing productivity. While in Organization Based on Gamification (OBG), organizational processes and activities are designed based on appropriate game mechanics. In other words, business process reengineering (BPR) for an organization can be done according to gamification models. In this approach we can use job design theories like Job Characteristics Model (JCM) (Hackman and Oldham 1976) and Flow Model (Csikszentmihalyi, 1990) in order to properly use the gamification mechanics to design a job.

\subsection{Enterprise gamification frameworks and methodologies}

Gamification in principle is generally understood as a framework to include three key dimensions of mechanics, dynamics and aesthetics associated with games as applied to non-game contexts (Simões et al., 2013). Several frameworks have been reported in the literature to integrate game and play design techniques into a gamification design process enhanced by persuasive technologies (Werbach, 2014; Dignan, 2011). Such propositions typically aim to stimulate change in individual behaviour and attitude. An example is Dignan's model (2011) which was extended by Werbach (2014) to incorporate intrinsic motivators that includes three elements of autonomy, competence and relatedness. Understanding the context and including contextual factors in designing games is a critical factor. An important aspect about these elements is that they should be adequately designed and crafted to align with a specific business environment, and not only added as a fit for all structures for engagement and motivation (Hamari, 2013). In other words, the enterprise gamification should be considered as a whole, from organizational strategy to value creation. If some parts of this anatomy does not work well, the entire system will not work properly (Raftopoulos, 2015). We can say gamification design focuses on how we can use mechanics such as Point, Badge, Level and Leaderboard, to increase user loyalty and engagement. Although various classes and frameworks have been proposed for gamification, Bui et al. (2015), by reviewing the literature in this area, have shown that existing classifications still do not cover all dimensions and require more development. One of the most important game design frameworks that is used in gamification is the MDA framework, which includes three parts: mechanics, dynamics and aesthetics (Hunicke et al., 2004). Since the mechanics are not itemized and classified in the MDA framework, Robinson and Bellotti (2013) proposed a preliminary taxonomy of gamification elements for varying anticipated commitment. Mora et al. (2017) have provided a systematic review of the gamification design frameworks in which a final list of 40 gaming frameworks was obtained and analyzed. In their study, one of the issues raised to improve frameworks is the development of a complete framework from a personalization perspective. So, MDA is one of the basic frameworks based on game design theory (Deterding et al., 2011; Zichermann and Cunningham, 2011). As shown in Fig. 2, it includes three main concepts, Mechanics, Dynamics and Aesthetics, which relate between game designers and gamers (Hunicke et al., 2004). In fact, MDA framework shows a one-way relationship from designer to user (Umar, 2015). Mechanics are at the level of data representation and algorithms and form the functioning components of the game such as Levels, Points, Leaderboards, and Badges.

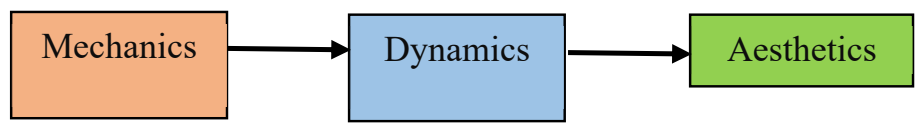

Fig. 2. MDA framework (Hunicke et al., 2004) 
Dynamics are based on mechanics and describe player's behaviours during the execution of the game. Aesthetics explain the emotional responses such as surprise, satisfaction, delight, and envy that arise in the player during the game. A modified form of MDA framework has been introduced by researchers in which the concept aesthetics is replaced with emotions to describe the user's emotional responses (Robson et al., 2015). This group believes since aesthetics are more relevant to the game context, emotions is a better word for gamification and unlike MDA in MDE all three parts affect each other (Robson et al., 2015). Chou (2015) developed a relatively comprehensive framework for gamification named as Octalysis. In this framework Chou describes eight types of core drives that motivate humans to do certain activities.The framework is shaped around an octagon that includes concepts of Epic Meaning, Accomplishment, Empowerment of Creativity, Ownership, Social Influence, Scarcity, Unpredictability and Avoidance. Marigo Raftopoulos (2014) developed an enterprise gamification framework called the Sustainable Gamification Design (SGD) framework. She explains seven key themes which creates value in gamification. These seven subjects include Engage and motivate employees, Performance data analysis, Improve learning and collaboration, Shape behaviour and performance, Improve employee productivity, Workplace and process transformation and finally Make work more fun and each value creation theme has a corresponding value destruction theme. The SGD framework introduces a four phase process: Discover (understanding context and actors of the system), Reframe (Analyze the information obtained from the previous phase), Envision (identify preferred solution) and Create (Design and launch a gamified solution). Neeli (2015) also offered a generic framework for enterprise gamification. The framework includes phases: Set the goals and objectives, Understand the challenges, Analyze the motivation, Designing gamified system, Measure and improve and finally Engagement boosters. Schmid and Schoop (2019) presented a new framework for electronic negotiation training and showed that learners' engagement and learning outcomes improve in the proposed framework. Chen (2019) also provided design guidelines for the use of user-centered design (UCD) in gamified systems using the Delphi method. A Design Framework has also been provided by Böckle et al(2018) for Adaptive Gamification Applications. García et al. (2017) developed a framework for gamification in software engineering and examined it in a real company and they showed that the proposed framework had a favorable impact on appropriate design and development. Morschheuser et al. (2018) also present a comprehensive method and key design principles for engineering gamified software in a similar study. They described the design problems of the gamification in the following four prominent categories:

(1) Difficulty in generally design of gamified systems because of the multiplicity of the inspirational source of gamification.

(2) Simultaneously considering entertainment and behavioral change in the gamified systems.

(3) The limitations and complexities that requirements of the non-game context imposed on the gamified systems' design.

(4) Need to understand a host of psychology and motivational factors in order to affect behavioral change.

So, only the use of game mechanics cannot lead to the gamification objectives. We need a systematic approach to identify target behaviours, players' profiles, and achieve real values of gamification (Huber \& Röpke, 2015). Some gamification frameworks such as MDA and Octalysis further illustrate a conceptual structure and pay less attention to the implementation stages and methodology. However some enterprise gamification frameworks try to provide a systematic approach to designing gamification, for example the framework provided by Marczewski (2013) offers a design process with two phases including planning and designing. Werbach and Hunter (2012) suggest a 6-step framework including: define business objectives, delineate target behaviours, describe your players, devise activity cycles, don't forget the fun, and finally deploy the appropriate tools. Kumar and Herger (2013) also offer a 5-step framework that is relatively similar in the content and different in the chronology including: know your player, identify mission, understand human motivation, apply mechanics and finally managing, monitoring and measuring. According to the relevant literature, the most important existing gaps in the methodology of enterprise gamification can be summarized as follows:

- While varied perspectives have been applied in the existing frameworks, almost all of them offer an approach to the concept from a general point of view and lack the requirements of a comprehensive and tailored methodology for this purpose.

- Limited insight is offered for the relationship between the three key pillars of enterprise gamification, namely organisational characteristics, human traits and gamification mechanics.

- The important aspect of customisation of gamification for specific needs of organisations, organisational units, individuals or occupational positions are not explicitly addressed. In other words, in the design process of the gamification solutions, players' emotions feedback is not received.

\section{Research method}

Given the literature review and the gaps mentioned in the previous section, the main objective in this study will be examining enterprise gamification solutions, taking into account demographic as well as personal level psychological behavioural characteristics of users. We explore how users' emotions should be included in the process of developing enterprise gamification solutions. In general, answering the requirement of an appropriate methodology for development of the enterprise gamification is the main focus of the study. To this end, the research applies expert opinion methods (Bogner et al., 2009). Based on the examination of literature, a protocol was developed and used to undertake interviews with a number of subject domain experts identified through the authors' network. The panel was formed of seven experts in the 
gamification field. Key questions in the focus of the work were around the requirements for an appropriate methodology for the design and implementation of enterprise gamification. The outcome from interviews were summarised and through a cross analysis key concepts for the enterprise gamification development were extracted. A conceptual methodology was then developed using a system approach by the key factors identified from the panel, which was further examined by the expert panel from which ideas were collected and included in a number of iterations to arrive at a near consensus model. The developed model was further examined using a survey method of a network of professionals in the design, development and implementation of Gamification solutions. The outcome offered strong support to the presented method, as reported later in the paper.

\section{Data gathering}

Data were gathered from the expert panel and summarized by the research group. The research group consisted of four researchers, all working in Agility Center of University of Liverpool in the field of gamification. A semi-structured focus panel with seven gamification experts was performed in August 2018. A three-hour discussion was held and audio-recorded and transformed into a transcript. The selection of experts was targeted and based on their abilities and background in the field of game and gamification design. Seven experts participated as panellists according to Table 1. Panellists were invited to participate via e-mail where the objective of the study as well as main questions were presented. They expressed the willingness to participate in recognition of suitable methodology for enterprise gamification. The main questions discussed were related to topics such as: the definition of the gamification, the enterprise gamification design process, the important requirements for gamification design, the most important design elements and how they were used, and the impact of demographic and psychological conditions of users on the gamification design process. At the end, all panellists were given the chance to expose any additional comment they felt were not yet mentioned.

Table 1

Demographic of panellists

\begin{tabular}{ccccc}
\hline Panellist Number & Age & Gender & Educational Level & $\begin{array}{c}\text { Years of experience in the field of } \\
\text { game/gamification }\end{array}$ \\
\hline 1 & 40 & Male & PhD & 5 \\
2 & 40 & Female & PhD & 18 \\
3 & 35 & Male & MSc & 5 \\
4 & 50 & Male & MSc & 5 \\
5 & 32 & Female & BSc & 16 \\
6 & 32 & Female & MSc & 11 \\
7 & 50 & Male & PhD & 5 \\
\hline
\end{tabular}

The research team received audio files and transcripts from the discussion and extracted the topics of the required activities for enterprise gamification design, which had been expressed by the panellists. They coded themes in two steps. First coding was independent using the key topics mentioned at least once, e.g. "Context importance in choosing elements". Then the main topics were extracted through the integration of similar initial topics based on agreement as much as possible. Table 2 shows the results.

Table 2

Extracted topics for enterprise gamification design based on expert panel

\begin{tabular}{|c|c|c|c|c|c|c|c|c|}
\hline 1 & $\begin{array}{l}\text { Using different elements and determination of suitable elements over time based on context (for } \\
\text { making motivation) }\end{array}$ & $\sqrt{ }$ & $\sqrt{ }$ & $\sqrt{ }$ & $\sqrt{ }$ & $\sqrt{ }$ & & \\
\hline 2 & Users typology and analysis (demographic and psychographics) & $\sqrt{ }$ & $\sqrt{ }$ & $\sqrt{ }$ & $\sqrt{ }$ & $\sqrt{ }$ & $\sqrt{ }$ & $\sqrt{ }$ \\
\hline 3 & Objectives role in gamification design / Determination of business metrics and priorities & $\sqrt{ }$ & & $\sqrt{ }$ & $\sqrt{ }$ & $\sqrt{ }$ & $\sqrt{ }$ & $\sqrt{ }$ \\
\hline 4 & Open minded philosophy and No certain template & $\sqrt{ }$ & $\sqrt{ }$ & & & & & \\
\hline 5 & Importance of context role like organizational scale and risk taking (company's conditions) & $\sqrt{ }$ & $\sqrt{ }$ & $\sqrt{ }$ & & $\sqrt{ }$ & $\sqrt{ }$ & $\sqrt{ }$ \\
\hline 6 & $\begin{array}{l}\text { Attention to the dynamics of organizations and need to measurement, change, iteration, test and } \\
\text { update }\end{array}$ & $\sqrt{ }$ & $\sqrt{ }$ & & $\sqrt{ }$ & $\sqrt{ }$ & $\sqrt{ }$ & $\sqrt{ }$ \\
\hline 7 & Problem-oriented being/ Activities list determination & $\sqrt{ }$ & $\sqrt{ }$ & $\sqrt{ }$ & & & & \\
\hline 8 & Importance of stakeholders/ end users and identification of their needs and human focused design & & $\sqrt{ }$ & $\sqrt{ }$ & $\sqrt{ }$ & $\sqrt{ }$ & $\sqrt{ }$ & $\sqrt{ }$ \\
\hline 9 & Technology ability & & $\sqrt{ }$ & & & & & \\
\hline 10 & Importance of visual rather than textual & & $\sqrt{ }$ & $\sqrt{ }$ & & & & $\sqrt{ }$ \\
\hline 11 & Using Octalysis framework (core drives) & & & $\sqrt{ }$ & & & & $\sqrt{ }$ \\
\hline 12 & Gathering ideas by brain storming about core drives and motivation methods & & & $\sqrt{ }$ & & & & $\sqrt{ }$ \\
\hline 13 & Considering time and budget limitations & & & & & $\sqrt{ }$ & & \\
\hline 14 & Prototype building and receiving feedback & & & & & $\sqrt{ }$ & & \\
\hline 15 & Design based on narration and story telling & & & & & & $\sqrt{ }$ & \\
\hline 16 & Using workshops for relation with users & & & & & & $\sqrt{ }$ & $\sqrt{ }$ \\
\hline 17 & Importance of motivation, rewards and recognition and sign up chain for users & & & & $\sqrt{ }$ & & & \\
\hline
\end{tabular}


According to the results shown in Table 2 and based on the panellists' opinions and the frequency of topics, the five key subjects in the enterprise gamification design, as shown in Fig. 3, include Using suitable elements based on context (suitable mechanics), Users typology and analysis (demographic and psychographics), Attention to the dynamics of organizations and need to measurement, change, Iteration, test and update, Objectives role in gamification design and determination of business metrics and priorities, and finally Importance of stakeholders and end users and identification of their needs (human focused design). In the next section we propose an enterprise gamification methodology based on these five key subjects.

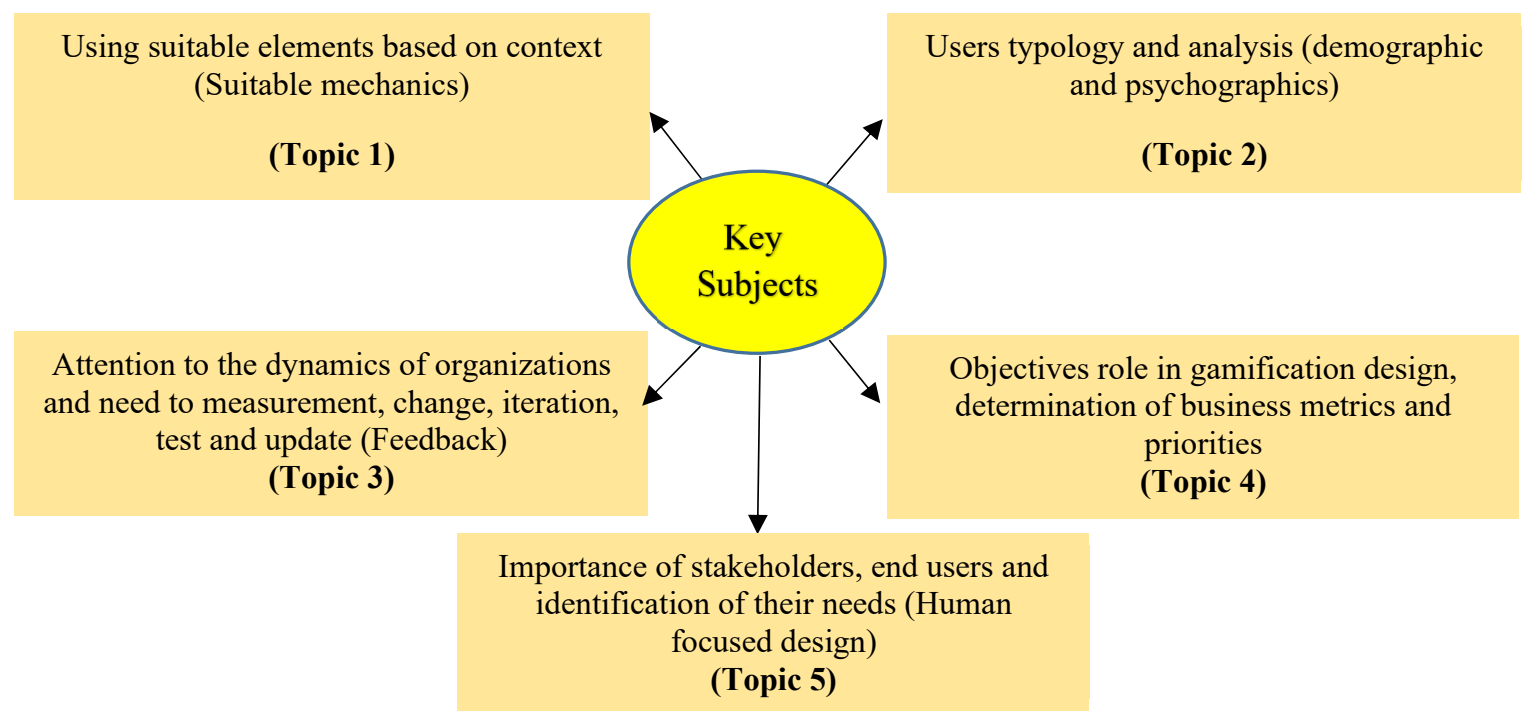

Fig. 3. Key subjects for the enterprise gamification design

\section{Proposed Methodology}

According to the results of the expert panel in the previous section of the research (Fig. 3), there are five key subjects that should be considered in the methodology.

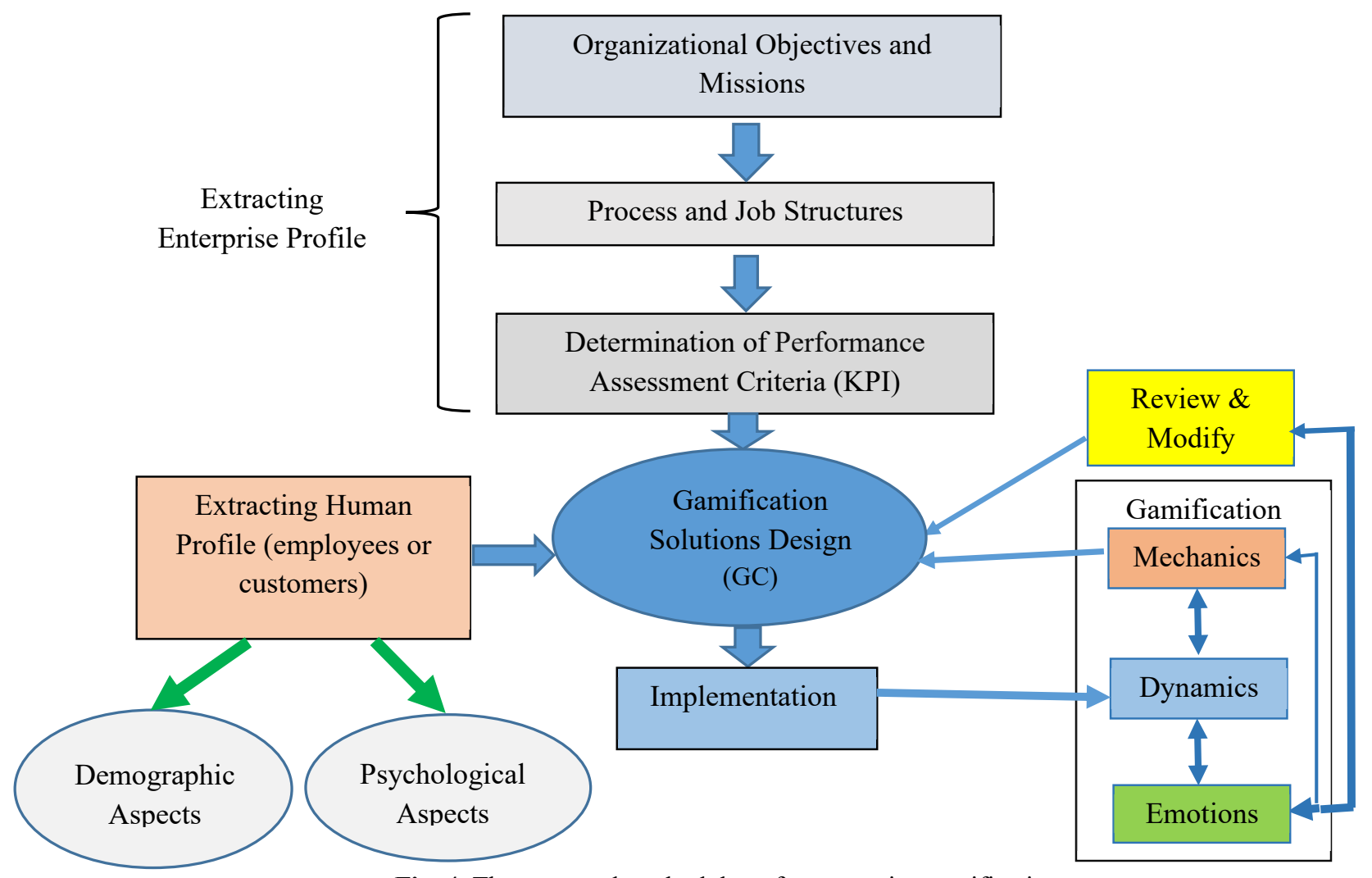

Fig. 4. The proposed methodology for enterprise gamification 
As shown in Fig. 4, the proposed methodology includes five foundations. First foundation is gamification that is viewed from the perspective of the MDE framework and includes mechanics and their roles in gamification design (related to the topic 1). Second foundation is human resource features in the organization which include demographic and psychological aspects of employees and customers (related to the topic 2). Third foundation is the feedback loop from emotions created in players (employees and customers) for necessary modifications in gamification solutions (related to the topic 3). Fourth foundation is organization and its conditions which include organizational aspects such as objectives, missions, processes, job structure, and performance assessment criteria (related to the topic 4). Fifth foundation is designing of gamification solutions based on users' needs as human focused design (related to the topic 5). In fact, by using this methodology we try to customize gamification solutions for an organization regarding its conditions. In the next sections we describe the main implementation steps of the methodology.

\subsection{Extracting enterprise profile}

According to the proposed methodology, thefirst and most important step is organizational studies at the enterprise. Undoubtedly, in the GBO approach the basis of the gamification solutions design is theorganization and its conditions. It isimportant that the enterprise goals are aligned with the objectives of thegamification solutions (Neeli, 2015). Therefore, it is necessary tostudy the organization, goals, missions, processes and job structures in thefirst step. Different organizations have different goals and priorities.Gamification solutions must meet these priorities. The best way to achieve thisgoal is to focus on performance assessment criteria which can be defined fromstrategic level to behavioural level. It can be key performance indicators(KPI) such as financialmetrics, customer metrics, social businessmetrics, process metrics, human resource metrics and innovation metrics in the organization too. Kaplan and Nortonintroduced the Balanced Scorecard (BSC) that allows managers to look at thebusiness from four important perspectives including financial, customer,internal business, innovation and learning (Kaplan \& Norton, 1992). In fact, thebalanced scorecard translates a company's strategy into specific measurable criteria. Therefore, we can determine performance indicators for each perspective and inaccordance with the priorities of the enterprise. For example, from a financialperspective, indicators such as return on investment and profit margin, from the perspective of internal processes indicators like thepercentage of new products in the innovation process or waste percentagerelated to the process of quality control or sales volume in the sales process, from the customer perspective customer satisfaction index and finally from thegrowth and learning perspective the organizational learning rate.

\subsection{Extracting human profile}

Another part of the methodology is identifying the demographic and psychological characteristics of the players. Gamification is highly dependent on the player. Because the player is the one who recognizes whether the system is satisfactory or not (Landsell \& Hägglund, 2016). Therefore, if the player does not enjoy it, the resultant will be a failure (Csikszentmihalyi, 1990). In fact, players in enterprise gamification are employees, customers, and partners. Although in this paper, we rely more on employees and customers. Therefore, the demographic characteristics of the players return to variables such as sex, age, and work experience of employees or customers. Also, from the perspective of psychology, we must assess the psychological characteristics of employees or customers. There are some studies from the perspective of identifying the player's psychological characteristics in the gamification (Neeli, 2015). One of the best known of these studies is Bartle's work (1996). He describes four types of players with different motivations: Achievers, Explorers, Socializers, and Killers. The Achievers search for success and want to be at the top of the leaderboards. Deplorers seek to discover new areas and scarce items. The Socializers seek more interaction with other players. The Killers are those who compete with others and enjoy defeating other players. Marczewski (2015) identifies six different types of users (user type hexad model): Disruptor, Free Spirit, Philanthropist, Achiever, Socializer and Player. Disruptors are motivated by making positive or negative changes. Free spirits are motivated by creativity, Autonomy and self-expression. Philanthropists are motivated by promoting the welfare of others. Achievers are motivated by Mastery and improvements. Socializers are motivated by interaction with others and Players are motivated by collecting Rewards. There are other research works like Fullerton (2008) and Caillou's (1961) that offer other categories of players and matching between each player and a specific type of games or mechanics. Of course, we have various theories in relation to personality traits and types that their explanations are beyond the scope of this paper (Riso, 2000). One of these theories has been presented in the form of the Five Factor Model (FFM) or "The Big Five" (Goldberg,1993). This model includes five categories of extraversion (outgoing/reserved), agreeableness(friendly/unkind), conscientiousness (organized/careless), openness(curious/cautious), and neuroticism (anxious/calm) (Crowne,2009). There is a questionnaire for measuring these traits (Costa \& McCrae, 1992) and also a short, ten-questions version of the Big Five (Rammstedt and John, 2007) that is our suggestion for use in the methodology.

\subsection{Extracting gamification mechanics}

We explained about concepts and frameworks of enterprise gamification in the literature review section. According to the proposed methodology, MDE framework is considered as the basis of the gamification. Mechanics are an important part of the framework used to design the enterprise gamification solutions. In the literature, mechanics are presented in different 
forms from components like Points, Badges, and Leaderboards to general concepts such as Challenge, Competition, Cooperation and Feedback (Werbach \& Hunter, 2012; Kim \& Lee, 2015). We suggest Octalysis framework (Chou, 2015) as the basis for the selection of mechanics of MDE framework in the methodology. This framework describes eight important concepts in gamification as shown in Table 3.

Table 3

Eight concepts of gamification according to Octalysis framework (Chou, 2015)

\begin{tabular}{|c|c|}
\hline Concept & Some related mechanics \\
\hline Epic Meaning \& Calling & Narrative, Higher Meaning, Elitism, Humanity Hero, Beginners Luck, Free Lunch \\
\hline Development \& & Points, Progress Bar, Step-By-Step Tutorial, Leaderboards, Badges, Quest Lists, Boss Fights, Fixed Action Rewards, \\
\hline Accomplishment & Win Prize, High-Five, Level-Up Symphony, Aura Effect \\
\hline Empowerment of Creativity & General's Carrot, Evergreen Mechanics, Real-Time Control, Chain Combos, Milestone Unlock, Boosters, Choice \\
\hline \& Feedback & nomy, Instant Feedback \\
\hline Ownership \& Possession & $\begin{array}{l}\text { Rirtual Goods, Avatar, Build From scratcn, Learning Curve, Earned Lunch, Collection Set, Monitoring, Protection, } \\
\text { Recruitment }\end{array}$ \\
\hline $\begin{array}{l}\text { Social Influence \& } \\
\text { Relatedness }\end{array}$ & $\begin{array}{l}\text { Friending, Mentorship, Group Quest, Bragging, Touting, Water Cooler, Social Treasure/Gifting, Social Prod, See- } \\
\text { Saw Bump }\end{array}$ \\
\hline Scarcity \& Impatience & $\begin{array}{l}\text { Dangling, Appointment Dynamics, Fixed Intervals, Moats, Throttles, Countdown, Prize Pacing, Options Pacing, } \\
\text { Patient Feedback }\end{array}$ \\
\hline Unpredictability \& Curiosity & $\begin{array}{l}\text { Easter Eggs, Sudden Rewards, Oracle Effect, Mini Quests, Glowing Choice, Rolling Rewards, Random Rewards, } \\
\text { Visual Storytelling, Obvious Wonder }\end{array}$ \\
\hline Loss \& Avoidance & $\begin{array}{l}\text { Sunk-Cost Tragedy, Progress Loss, Fear Of Missing Out, Evanescence Opportunity, Scarlet Letter, Status Quo Sloth, } \\
\text { Weep Tune, Visual Grave }\end{array}$ \\
\hline
\end{tabular}

\subsection{Gamification solutions design}

Gamification design is different with the game design. The gamification designer does not look at the gamification from the game perspective (Herger, 2014). While in the game design the main goal is to provide entertainment and pleasure, the enterprise gamification solutions aim to achieve the enterprise objectives. Gamification Design Patterns are a combination of gamification design mechanics to reflect certain gamification solutions. Since there are differences between game and gamification, therefore the game design patterns are different with gamification design patterns. There are few works about gamification design patterns (Herger, 2015). In the proposed methodology, if $\mathrm{X}_{\mathrm{j}}$ denotes the jth criterion of performance assessment in the enterprise and $\mathrm{M}_{1}$ denotes the lth mechanic in MDE gamification model, and $\mathrm{P}_{\mathrm{k}}$ denotes the kth human feature, therefore $G_{i}$ that shows the ith gamification solution will be function of those parameter and we will have:

$$
\begin{aligned}
& G_{i}=f\left(x_{j} \cdot m_{l} \cdot p_{k}\right) \\
& \quad \text { If } j=[1 \ldots n] . l=[1 \ldots r] . k=[1 \ldots t] \Rightarrow i=[1 \ldots n r t]
\end{aligned}
$$

Therefore, in this three-dimensional space, since all three variables are discrete and each variable can contain different values, different gamification solutions may occur. We will face a discrete function. So in the design space, theoretically, we have many options for customized gamification. But in practice a limited number of these options are feasible according to organizational conditions. In the methodology steps section, we will talk more about how to design gamification solutions.

\subsection{Feedback}

Gamification should be viewed as an ongoing program. It needs maintenance, measuring and monitoring. In other words, the gamified system should be adapted continuously to enterprise goals and monitor employee motivation for prevention of user fatigue (Kumar \& Herger, 2013; Winn, 2009). In the methodology, this task is done by the feedback loop from emotions created in players (employees and customers) for necessary modifications in gamification's solutions.

\subsection{Methodology steps}

In this section, we will explain the methodology steps based on the information in the previous sections. For proper decision making in some methodology steps, we define a committee called the Gamification Committee (GC) in the enterprise. The $\mathrm{GC}$ consists of several relevant managers of the organization, as well as experts in the administrative field (for decision making about gamification solutions related to employees) and marketing (for decision making about gamification solutions related to customers). An expert system or decision support system can play the role of GC. The methodology steps are as follows (as shown in Fig. 5):

Step 1: Gamification Committee (GC) determines the most important criteria $\left(\mathrm{X}_{\mathrm{j}}\right)$ for enterprise performance assessment based on the goals, missions and organizational and job structures and also enterprise priorities. As mentioned in the relevant section (5.1), these criteria can be determined on the basis of four perspectives of BSC model. For customerrelated gamification solutions, these criteria are interpreted from the perspective of customer performance, and customer performance assessment indicators are selected (for example customer's purchase rate). And similarly for 
employee-related gamification solutions, these criteria are interpreted from the perspective of employee performance, and employee performance assessment indicators will be determined (for example employee discipline rate).

Step 2: Regarding the result of the first step, the basic mechanics $\left(\mathrm{M}_{1}\right)$ for use in the gamification solutions are considered. According to the mentioned information in the section 5.3, GC determines the basic mechanics based on the Octalysis framework as shown in the Table 3.

Step 3: We create basic gamification solutions $\left(\mathrm{G}_{\mathrm{i}}\right)$ based on the selected indicators (step 1) and mechanics (step 2). For example, for the "employee discipline rate" indicator and the "point" mechanic, the gamification solution can be in the form of: "giving daily points to employees due to paying attention to administrative discipline".

Step 4: The level of users' satisfaction (customers or employees) from the proposed gamification solutions in the step 3, is obtained through a questionnaire (based on the Likert scale). In fact, the users' satisfaction represents emotions in the MDE framework. In the first part of this questionnaire, user's demographic and psychological information (based on the Big Five model) is also obtained. A sample of this questionnaire is shown in the appendix.

Step 5: The received data from the step 4 are analyzed and the popular gamification solutions for various groups of users (customers or employees) are identified. If the amount of data is sufficient, it will be possible to use clustering techniques to distinguish users in different groups based on demographic and psychological characteristics, and to determine customized gamification solutions for each group.

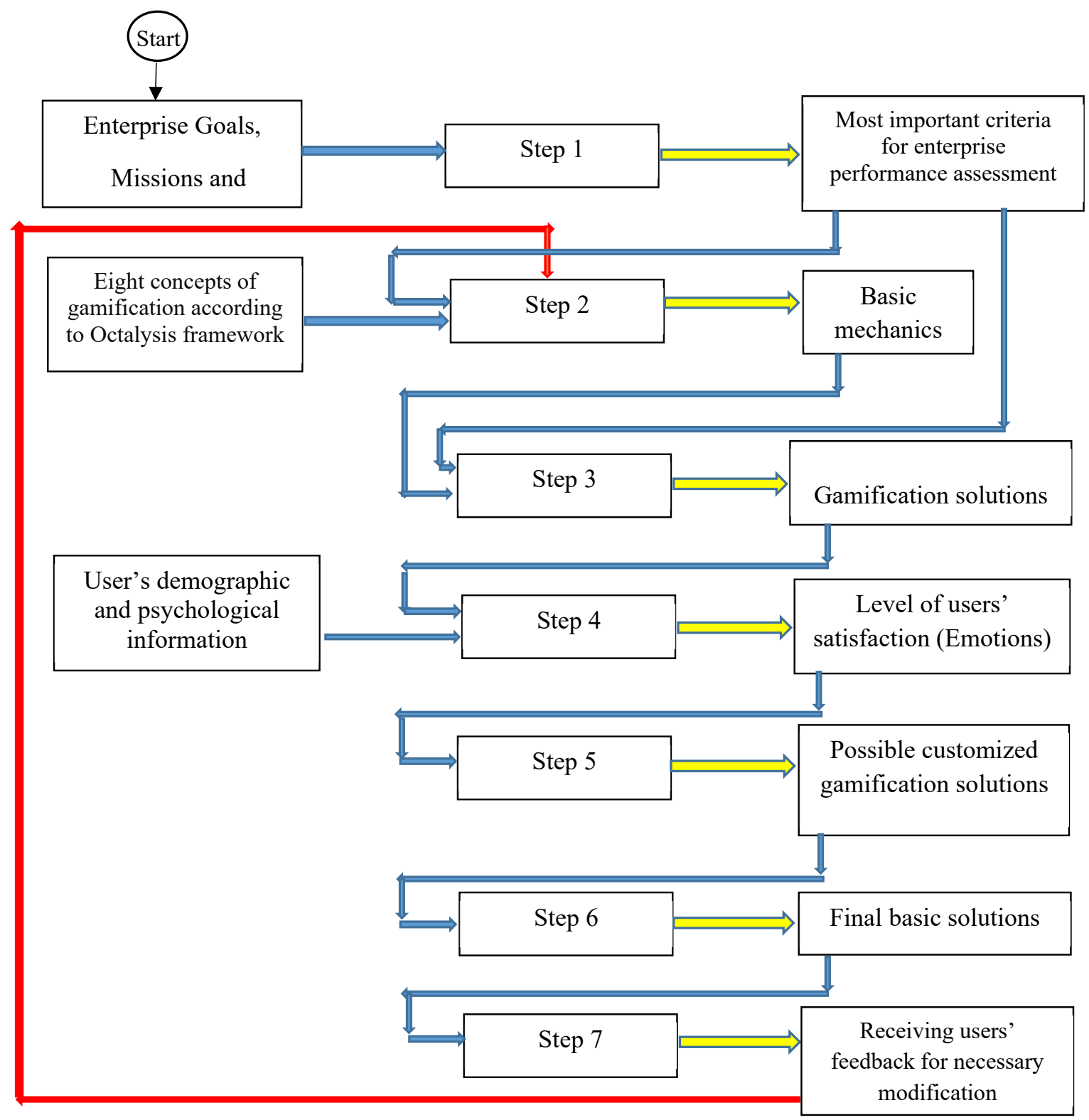

Fig. 5. Diagram of methodology steps, Steps Inputs: Blue, Steps Outputs: Yellow, Feedback: Red 
Step 6: After receiving the results of step 5, the GC decides on the selection and integration of the final basic solutions based on criteria such as the degree of popularity of the solution, the solution effectiveness, the solution feasibility, the running time and the cost of implementation. Decision making and selection of final gamification solutions can be made using decision making techniques such as Analytic Hierarchy Process (AHP) (Saaty, 1980) as shown in Fig. 6.

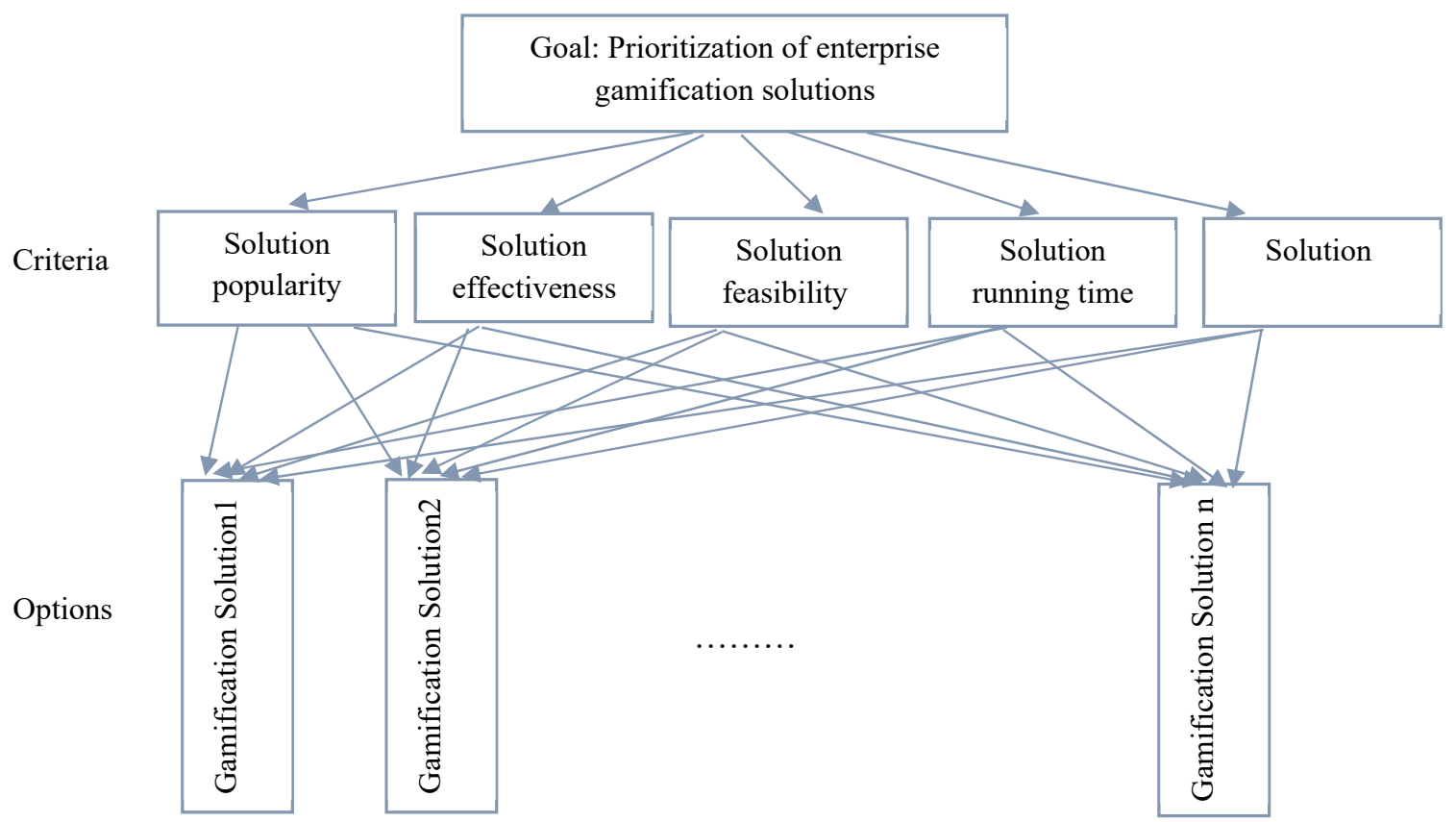

Fig. 6. Decision making model based on AHP

Economic aspect of enterprise gamification is important. In the designing and implementing gamification we should consider gamification cost. For example, development, administration, gamification technology licenses, prizes and upgrades cost. That's why in this step The GC must pay attention to the cost criterion.

Step 7: Selected gamification solutions in step 6 will be implemented. After a while, the GC receives users' feedback and will review results for necessary modification.

\section{Methodology assessment}

To validate the methodology, we apply a qualitative study through getting the opinions of the relevant experts in the gamification field. Expert panel sizes for Delphi studies typically range from 12- 20 members (Skulmoski et al., 2007). According to (Kitchen ham et al., 2005), we evaluate the methodology using some selected criteria including methodology completeness, understandability, flexibility, ease of implementation, appropriateness for enterprises and authentic theoretical foundation. The main criteria for selecting experts are expertise and work experience in the field of gamification. We determined the primary list of experts from among the authors of gamification papers in related international journals and conferences and gamification designers. Therefore, 53 experts were identified and we sent an invitation letter to participate in this research to all of them by email. A total of 15 of them from different countries accepted to participate in the research and completed the online questionnaire. The summary of the demographic data of the experts is presented in Table 4 .

Table 4

Demographic of experts

\begin{tabular}{cccr}
\hline $\begin{array}{c}\text { Years of experience } \\
\text { in the field of game/gamification }\end{array}$ & Age & Educational Level & Gender \\
\hline $1-2: 13 \%$ & $26-35: 20 \%$ & $\mathrm{PhD} / \mathrm{PhD}$ student: $85.7 \%$ & Male: $85.7 \%$ \\
$3-5: 53 \%$ & $36-45: 47 \%$ & MSc: $14.3 \%$ & Female: $14.3 \%$ \\
$6-10: 27 \%$ & $46-60: 33 \%$ & & \\
Over $10: 7 \%$ & &
\end{tabular}

Table 5 shows the methodology assessment results in the 6 criteria. An overview of the results indicates a mean value about 70 percent for a sum of excellent and good assessments of criteria and consequently a positive assessment of the 
methodology. According to Table 5, the sum of excellent and good assessments for the four criteria, methodology completeness, understandability, appropriateness for enterprises and authentic theoretical foundation, is above $70 \%$, which demonstrates an assessment between good and excellent. This summation for the two criteria, flexibility and ease of implementation is 53 and 41 percent, respectively, indicating an assessment between average and good. Some experts declared in their comments that to improve ease of implementation, the enterprise should provide the necessary mechanisms for the implementation of the methodology. Also, before the implementation of the methodology, the enterprise management should make its decision to take advantage of the gamification. This decision itself, can be made on the basis of an evaluation in the organization.

Table 5

Methodology assessment results

\begin{tabular}{|c|c|c|c|c|c|}
\hline Criteria & Excellent (\%) & Good (\%) & Average (\%) & Poor (\%) & Very Poor (\%) \\
\hline Methodology completeness & 20 & 54 & 20 & 6 & 0 \\
\hline Understandability & 27 & 67 & 0 & 6 & 0 \\
\hline Flexibility & 6 & 47 & 47 & 0 & 0 \\
\hline Ease of implementation & 7 & 34 & 40 & 13 & 6 \\
\hline Appropriateness for enterprises & 14 & 67 & 6 & 13 & 0 \\
\hline Authentic theoretical foundation & 20 & 54 & 26 & 0 & 0 \\
\hline Mean & 15.67 & 53.83 & 23.17 & 6.33 & 1 \\
\hline
\end{tabular}

\section{Conclusion}

With the advent of information technology, gamification has been considered as one of the most widely used fields in today's world. Enterprise gamification, that is proper use of the gamification in enterprises to increase productivity and better communication with customers and employees, has particular importance. This paper offers a comprehensive methodology for designing and implementing enterprise gamification through reviewing the related literature and expert panel. The proposed methodology consists of all the important dimensions, including organizational features, user's characteristics and important mechanics of gamification for designing the gamification solutions. Therefore, the final solutions are tailored to the enterprise characteristics and user's traits based on a targeted study. The evaluation of the methodology showed that the proposed process could be a suitable and perfect way to design gamification solutions in the firms, but the enterprise needs to provide the necessary conditions for its implementation.

\section{References}

Anitha, J. (2014). Determinants of employee engagement and their impact on employee performance. International Journal of Productivity and Performance Management., 63(3).

Bartle, R. (1996). Hearts, clubs, diamonds, spades: Players who suit MUDs. Journal of MUD Research, 1(1), 19.

Böckle, M., Micheel, I., Bick, M., \& Novak, J. (2018). A design framework for adaptive gamification applications. Proceedings of the 51st Hawaii International Conference on System Sciences (HICSS), I r r I I rV.

Bogner A., Littig B., \& Menz W. (Eds.). (2009). Interviewing experts (ECPR Research Methods). UK: Palgrave Macmillan. Bui, A., Veit, D., \& Webster, J. (2015). Gamification-A Novel Phenomenon or a New Wrapping for Existing Concepts?

Caillois, R. (1961). Man, play, and games. University of Illinois Press.

Chen, Y. (2019). Exploring Design Guidelines of Using User-Centered Design in Gamification Development: A Delphi Study. International Journal of Human-Computer Interaction, 35(13), 1170-1181.

Chou, Y. (2015). Actionable gamification- beyond points, badges, and leaderboards, Octalysis Media. Raftopoulos, M. (2014). Towards gamification transparency: A conceptual framework for the development of responsible gamified enterprise systems, Journal of Gaming and Virtual Worlds, 6(2), 159-178. doi: 10.1386/jgvw.6.2.1591.

Costa, P.T., \& McCrae, R.R. (1992). Revised neo personality inventory (neo pi-r) and neo five-factor inventory (neo-ffi), Psychological assessment resources odessa, FL.

Crowne, D.P. (2009). Personality theory. Oxford University Press.

Csikszentmihalyi, M. (1990). Flow: The psychology of optimal experiences. New York: Harper Perennial.

Deterding, S., Dixon, D., Khaled, R., \& Nacke, L. (2011). From game design elements to gamefulness: Defining "gamification", MindTrek'11.

Dignan, A. (2011). Game frame: Using games as a strategy for success. New York: Free Press.

Fullerton, T. (2008). Game design workshop: A playcentric approach to creating innovative games. Elsevier Morgan Kaufmann.

García, F., Mario, P. P., Cerdeira-Pena, A., \& Penabad, M. (2017). A framework for gamification in software engineering. Journal of Systems and Software (JSS), 132, 21-40.

Goldberg, L.R. (1993). The structure of phenotypic personality traits, American psychologist, $48,1$.

Hackman, R., \& Oldham, G. R. (1976). Motivation through the design of work: Test of a theory. Organizational Behavior and Human Performance, 16, 250-279. 
Hamari, J. (2013). Transforming homo economicus into homo ludens: A field experiment on gamification in a utilitarian peer-to-peer trading service, Electronic Commerce Research \& Applications, 12(4), 236-245.

Hamari, J., Koivisto, J., \& Harri, S. (2014). Does gamification work? - A literature review of empirical studies on gamification, 47th Hawaii international conference on system sciences (pp. 3025-3034), Waikoloa, January 6-9. IEEE.

Henriot, J. (1969). Le jeu. Paris: PUF.

Herger, M. (2014). Enterprise gamification, Engaging people by letting them have fun, Book 1, The Basics. CreateSpace, Luxembourg.

Herger, M. (2015). Gamification design patterns, from: http://www.enterprisegamification.com/mediawiki/index.php?title=Category:GamificationDesignPatterns

Huber, S., \& Röpke K. (2015). How gamification can help companies to become more sustainable: A case study on ride sharing, Gamification in education and business, springer.

Hunicke, R., LeBlanc, M., \& Zubek, R. (2004). MDA: a formal Approach to game design and game research, in Proceedings of the 19th AAAI workshop on challenges in Game AI, San Jose.

Iacovides, I. (2011). Digital games: Exploring the relationship between motivation, engagement and informal learning. Psychology Of Education Review, 35(1), 21-24.

Juul, J. (2010). A casual revolution: Reinventing video games and their players. Cambridge, MA: MIT Press.

Kaplan, R. S., \& D.P. Norton. (1992). The balanced scorecard: Measures that drive performance. Harvard Business Review, 71-79.

Kapp, K. M. (2012). The gamification of learning and Instruction: game-based methods and strategies for training and education. San Francisco, CA, John Wiley \& Sons.

Kark, R. (2011). Games managers play: play as a form of leadership development. Academy of Management Learning \& Education, 10(3), 507-527.

Kim, J. T., \& Lee, W. H. (2015). Dynamical model for gamification of learning (DMGL), Multimedia Tools and Applications, 74, 8483-8493.

Kitchen ham, B., Linkman, S., \& Lwinkman, S. (2005). Experiences of using an evaluation framework. Information and Software Technology, 47(11), 761-774.

Kumar, J. M., \& Herger, M. (2013). Gamification at Work: Designing engaging business software. Aarhus, Denmark, The Interaction Design Foundation. ISBN: 978-87-92964-06-9. Book available online at http://www.interactiondesign.org/books/gamification_at_work.html

Landsell, J., \& Hägglund, E. (2016). Towards a gamification framework: Limitations and opportunities when gamifying business processes, Faculty of social sciences, Department of informatics, Umeå University.

Marczewski, A. C. (2015). Even ninja monkeys like to play: Gamification, game thinking and motivational design, Createspace.

Marczewski, A. (2013). Gamification: A simple introduction. Raleigh: Lulu.

Meloni, W., \& Gruener, W. (2012). Gamification in 2012: Consumer and enterprise market trends, M2 Research.

Mora, A., Riera, D., González, C. and Arnedo-Moreno, J. (2017). Gamification: a systematic review of design frameworks, Journal of Computing in Higher Education, 29, 51.0 $0 \Lambda_{-} \uparrow$

Morschheuser, B., Hassan, L., Werder, K., \& Hamari, J. (2018). How to design gamification? A method for engineering gamified software. Information \& Software Technology, 95, 219-237.

Neeli B. K. (2012). A Method to engage employees using gamification in BPO Industry," Proc. of 3rd Int. Conference on services in emerging markets (ICSEM), pp. 142-146.

Neeli, B.K. (2015). Gamification in the enterprise: Differences from consumer market, implications, and a method to manage them, Gamification in education and business, springer.

Nicholson, S. (2015). A RECIPE for meaningful gamification, first chapter of gamification in education and business, Springer.

Raftopoulos, M. (2015). Gamification project success and failures [Video], Retrieved from https://www.youtube.com/watch?v=GztWDpQxBDA.

Rammstedt, B., \& John, O. P. (2007). Measuring personality in one minute or less: A 10-item short version of the Big Five Inventory in english and german, Journal of Research in Personality 41(1), 203-212.

Riso, D.R. (2000). Understanding the Enneagram: The Practical guide to personality types. Houghton Mifflin Harcourt.

Robinson, D., \& Bellotti, V. (2013). A preliminary taxonomy of gamification elements for varying anticipated commitment. Proceedings CHI 2013 Workshop on Designing Gamification: Creating Gameful and Playful Experiences. ACM.

Robson, K., Plangger, K., Kietzmann, J., McCarthy, I., \& Pitt, L. (2015). Is it all a game? Understanding the principles of gamification, Business horizons, 58(4), 411-420.

Ryan, R. M., \& Deci, E. L. (2000). Intrinsic and extrinsic motivations: Classic definitions and new directions, Contemporary Educational Osychology, 25(1), 54-67.

Saaty, T.L. (1980). The analytical hierarchy process. McGraw Hill, New York.

Sanchez, A., Cannon-Bowers, J., \& Bowers, C. (2010). Establishing a science of game based learning in serious game design and development, Technologies for training and learning, Information Science Reference.

Schmid, A., and Schoop, M. (2019). A Framework for Gamified Electronic Negotiation Training. 2019 Cham. Springer International Publishing, 207-222. 
Seaborn, K., \& Fels, D. (2015). Gamification in theory and action: A survey. International Journal of Human-Computer Studies, 74, 14-31.

Silva Ochoa, H. (2013). La 'gamification' de la vie: Sous couleur dejouer?, Sciences du jeu 1.

Simões, J., Redondo, R. D., \& Vilas, A. F. (2013). A social gamification framework for a K-6 learning platform, Computers in Human Behavior, 29(2), 345-353.

Skulmoski, G.J., Hartman, F.T., \& Krahn, J. (2007). The delphi method for graduate research. Journal of information Technology Education, $\underline{6}, 1-21$.

The Gallup organization, (2013). The state of the global workplace: Employee engagement insights for business leaders worldwide, Washington, DC: Gallup Inc.

Umar, R. (2015). Level up your strategy: Towards a descriptive framework for meaningful enterprise gamification, Technology Innovation Management Review, 5(8), 5-16.

Werbach, K. (2014). (Re)Defining gamification: A process approach. In A. Spagnolli, L. Chittaro, and L. Gamberini (Eds.), Persuasive technology, 8462: 266-272. Springer International Publishing. http://dx.doi.org/10.1007/978-3-319-07127523

Werbach, K., \& Hunter, D. (2012). For the win. How game thinking can revolutionize your business. Philadelphia: Wharton Digital Press.

Winn, B. M. (2009). The design, play, and experience framework, In R. E. Ferdig, Handbook of research on effective electronic gaming in education, 3, 1010-1024. Florida, USA: Information Science Reference.

Zichermann, G., \& Linder, J. (2013). The Gamification revolution: How leaders leverage game mechanics to crush the competition (1st ed.). McGraw-Hill.

Zichermann, G., \& Cunningham, C. (2011). Gamification by design, O'Reilly Media, Inc, 1005 Gravenstein Highway North, Sebastopol, CA 95472.

Zimmerman, E. (2004). Narrative, Interactivity, play, and games. In Wardrip-Fruin, N. and Harrigan, P.(eds), First Person, MIT Press.

\section{Appendix: A sample of the questionnaire.}

Demographic information:

Job Title:

Gender: $\quad$ Female $\square, \quad$ Male $\square$

Educational Level: $\quad$ under BSc $\square, \quad \operatorname{BSc} \square, \quad \operatorname{MSc} \square, \quad \operatorname{PhD} \square$

Age: $\quad$ Under $25 \square, \quad 26-35 \square, \quad 35-45 \square, \quad 45-60 \square$, over 60

How well do the following statements describe your personality? Please complete the following table by placing a CROSS in the appropriate cell.

\begin{tabular}{|c|c|c|c|c|}
\hline I see myself as someone who ... & $\begin{array}{c}\text { Strongly } \\
\text { disagree }\end{array}$ & Disagree & $\begin{array}{c}\text { Neither agree } \\
\text { nor disagree }\end{array}$ & $\begin{array}{c}\text { Strongly } \\
\text { agree }\end{array}$ \\
\hline$\ldots$ is reserved & & & & \\
\hline$\ldots$ is generally trusting & & & & \\
\hline$\ldots$ tends to be lazy & & & & \\
\hline$\ldots$ is relaxed, handles stress well & & & & \\
\hline$\ldots$ has few artistic interests & & & & \\
\hline$\ldots$ is outgoing, sociable & & & & \\
\hline$\ldots$ tends to find fault with others & & & & \\
\hline$\ldots$ does a thorough job & & & & \\
\hline$\ldots$ gets nervous easily & & & & \\
\hline$\ldots$ has an active imagination & & & & \\
\hline
\end{tabular}


A sample of user's satisfaction assessment questionnaire for the "employee discipline rate" indicator

\begin{tabular}{|c|c|c|c|c|c|c|c|}
\hline \multirow{2}{*}{ Row } & \multirow{2}{*}{$\begin{array}{l}\text { Mechanic/Concept } \\
\text { (based on Octalysis) }\end{array}$} & \multirow{2}{*}{ Gamification solution } & \multicolumn{5}{|c|}{$\begin{array}{c}\text { Satisfaction level of } \\
\text { the gamification solution }\end{array}$} \\
\hline & & & $\begin{array}{l}\text { very } \\
\text { high }\end{array}$ & high & somewhat & low & $\begin{array}{l}\text { very } \\
\text { low }\end{array}$ \\
\hline 1 & $\begin{array}{l}\text { (Points) } \\
\text { Accomplishment }\end{array}$ & $\begin{array}{l}\text { Giving daily points to employees due to paying } \\
\text { attention to administrative discipline (e.g., timely } \\
\text { attendance at the organization) and reward allocation } \\
\text { for points }\end{array}$ & & & & & \\
\hline 2 & $\begin{array}{l}\text { (Badges) } \\
\text { Accomplishment }\end{array}$ & $\begin{array}{l}\text { Designation and allocation of special badges for top } \\
\text { employees in relation to the attention to } \\
\text { administrative discipline }\end{array}$ & & & & & \\
\hline 3 & $\begin{array}{l}\text { (Leaderboards) } \\
\text { Accomplishment }\end{array}$ & $\begin{array}{l}\text { Public announcement of employees list based on the } \\
\text { degree of attention to administrative discipline and } \\
\text { identification of superior ones }\end{array}$ & & & & & \\
\hline 4 & Avoidance & $\begin{array}{l}\text { Use punitive methods to deal with employees who do } \\
\text { not comply with administrative discipline }\end{array}$ & & & & & \\
\hline 5 & Epic Meaning & $\begin{array}{l}\text { The use of epic methods and employee awareness of } \\
\text { values and spirituality in order to pay attention to } \\
\text { administrative discipline }\end{array}$ & & & & & \\
\hline 6 & $\begin{array}{l}\text { (lottery) } \\
\text { Unpredictability }\end{array}$ & $\begin{array}{l}\text { lottery at the end of the specified periods of time } \\
\text { between the disciplinary staff and the giving reward }\end{array}$ & & & & & \\
\hline 7 & $\begin{array}{l}\text { (Random reward) } \\
\text { Unpredictability }\end{array}$ & $\begin{array}{l}\text { Provide random and unpredictable rewards at the end } \\
\text { of the assessment period to employees who are } \\
\text { superior in terms of administrative discipline. }\end{array}$ & & & & & \\
\hline 8 & $\begin{array}{l}\text { (Progress Bar) } \\
\text { Accomplishment }\end{array}$ & $\begin{array}{l}\text { Review and display the behavioral changes of each } \\
\text { employee in the context of administrative discipline } \\
\text { and assess his progress }\end{array}$ & & & & & \\
\hline 9 & $\begin{array}{l}\text { (Countdown) } \\
\text { Scarcity }\end{array}$ & $\begin{array}{l}\text { Using countdowns and giving limited opportunity to } \\
\text { employees who have been paying little attention to } \\
\text { administrative discipline for some time }\end{array}$ & & & & & \\
\hline 10 & $\begin{array}{l}\text { (Avatar) } \\
\text { Ownership }\end{array}$ & $\begin{array}{l}\text { Creating a sense of ownership in employee behavior } \\
\text { to increase administrative discipline, through gadgets } \\
\text { and virtual environment techniques like avatars }\end{array}$ & & & & & \\
\hline 11 & Social Influence & $\begin{array}{l}\text { Use of social networking mechanisms with other } \\
\text { employees to enhance administrative discipline }\end{array}$ & & & & & \\
\hline 12 & Empowerment & $\begin{array}{l}\text { Implementing the mechanisms of employee } \\
\text { empowerment in order to comply with administrative } \\
\text { discipline }\end{array}$ & & & & & \\
\hline
\end{tabular}

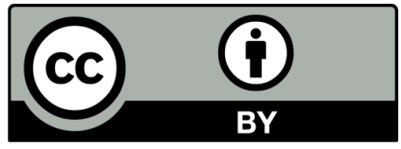

(C) 2021 by the authors; licensee Growing Science, Canada. This is an open access article distributed under the terms and conditions of the Creative Commons Attribution (CC-BY) license (http://creativecommons.org/licenses/by/4.0/). 